\title{
La ferritina sérica: más allá de la deficiencia de hierro
}

\author{
Serum ferritin: beyond iron deficiency
}

\author{
"El buen médico trata la enfermedad; el gran médico \\ trata al paciente que tiene la enfermedad." \\ (William Osler)
}

\section{L:} a determinación de la ferritina sérica es la prueba central en el estudio del metabolismo de hierro y una de las pruebas más solicitadas al laboratorio clínico [1]. La determinación de la ferritina sérica no solamente es de gran utilidad en el estudio y clasificación de las anemias, especialmente en el caso de la ferropenia, con o sin anemia [2], razón por la cual se solicita en la mayoría de las veces, sino que es un excelente indicador de la salud, debido a que se comporta como un reactante de fase aguda [3] [4] [5] [6], en particular frente a las enfermedades inflamatorias, infecciosas y neoplásicas, con o sin anemia asociada y como parte integral de enfermedades con sobrecarga de hierro tanto adquiridas como el síndrome metabólico [7] y la mayoría de las hepatopatías, como la alcohólica [8] [9] o las no alcohólicas entre las cuales se incluyen la producida por el virus de la hepatitis $B$ [10] y por el virus de la hepatitis C [11], y como genéticas entre las cuales se incluye, entre otras, la hemocromatosis hereditaria [12].

Ampliar las indicaciones de la determinación de la ferritina sérica más allá del estudio de la deficiencia de hierro, es un gran avance clínico si se tiene en cuenta que cuando hay hiperferretinemia, definida de acuerdo con el estudio HEIRS (del inglés, Hemochromatosis and Iron Overload Screening), como un nivel de ferritina sérica por encima de $200 \mu \mathrm{g} / \mathrm{L}$ en mujeres y por encima $300 \mu \mathrm{g} / \mathrm{L}$ en hombres [13], esta puede ser el punto de partida para el diagnóstico y manejo de múltiples enfermedades, tanto adquiridas como hereditarias, y el punto de partida de enfermedades como la cirrosis [14], el cáncer de hígado [15] y la diabetes mellitus [16], entre otras muchas manifestaciones clínicas, particularmente cuando la hiperferritinemia está asociada con sobrecarga de hierro, de ahí la importancia de incorporar la determinación de la ferritina sérica en la evaluación general de los pacientes, no necesariamente en aquellos con síndromes anémicos como se ha expresado haciendo alusión a la utilización tradicional de esta prueba [1].

En el presente número de MEDICINA \& LABORATORIO se presenta una revisión completa de la hiperferritinemia, en donde se analizan la ferroquinética, las causas de la hiperferritinemia de acuerdo con la frecuencia, el concepto de sobrecarga de hierro y los aspec- 
tos básicos del manejo de estos pacientes basados en un algoritmo [17]. Por un lado, es importante que la comunidad médica incorpore la medición de la ferritina sérica, y los estudios complementarios de laboratorio clínico, patología e imagenología, como una herramienta clínica de utilidad más allá del diagnóstico y manejo de la deficiencia de hierro; y los laboratorios clínicos, los servicios de patología y de imagenología para que incluyan estos estudios en sus respectivos portafolios de servicios. Aunando la educación alrededor del buen uso de las herramientas de diagnóstico y manejo que la tecnología pone al servicio de la medicina, habremos logrado nuestro objetivo al brindar una mejor atención a los pacientes, única razón de ser de nuestra actividad profesional.

\section{Ceampin \\ Germán Campuzano Maya, MD}

Médico, especialista en Hematología y Patología Clínica

Editor, Medicina \& Laboratorio

Medellín, Colombia, octubre 2017

\section{Bibliografía}

1. Ogilvie C, Fitzsimons K, Fitzsimons EJ. Serum ferritin values in primary care: are high values overlooked? J Clin Pathol 2010;63:1124-1126.

2. Ho CH. The differential diagnostic values of serum transferrin receptor, serum ferritin and related parameters in the patients with various causes of anemia. Haematologica 2001;86:206-207.

3. Birgegard G, Hallgren R, Killander A, Stromberg A, Venge P, Wide L. Serum ferritin during infection. A longitudinal study. Scand J Haematol 1978;21:333-340.

4. Herbert V, Jayatilleke E, Shaw S, Rosman AS, Giardina P, Grady RW, et al. Serum ferritin iron, a new test, measures human body iron stores unconfounded by inflammation. Stem Cells 1997;15:291-296.

5. Seyhan S, Pamuk ON, Pamuk GE, Cakir N. The correlation between ferritin level and acute phase parameters in rheumatoid arthritis and systemic lupus erythematosus. Eur J Rheumatol 2014;1:92-95.

6. Thachil J. The beneficial effect of acute phase increase in serum ferritin. Eur J Intern Med 2016;35:e16-e17.

7. Moirand R, Mortaji AM, Loreal O, Paillard F, Brissot P, Deugnier Y. A new syndrome of liver iron overload with normal transferrin saturation. Lancet 1997;349:95-97.

8. Lefkowitch JH. Morphology of alcoholic liver disease. Clin Liver Dis 2005;9:37-53.

9. Yip WW, Burt AD. Alcoholic liver disease. Semin Diagn Pathol 2006;23:149-160.

10. Wu J, Chen L, Chen Y, Yang J, Wu D. Serum ferritin concentration predicts mortality in patients with hepatitis B virus-related acute on chronic liver failure. Arch Med Res 2014;45:251-256.

11. Uchino K, Tateishi R, Fujiwara N, Minami T, Sato M, Enooku K, et al. Impact of serum ferritin level on hepatocarcinogenesis in chronic hepatitis C patients. Hepatol Res 2016;46:259-268.

12. Barton JC. Hemochromatosis and iron overload: from bench to clinic. Am J Med Sci 2013;346:403-412.

13. McLaren GD, Gordeuk VR. Hereditary hemochromatosis: insights from the Hemochromatosis and Iron Overload Screening (HEIRS) Study. Hematology Am Soc Hematol Educ Program 2009;195-206.

14. Mathurin P, Beuzin F, Louvet A, Carrie-Ganne N, Balian A, Trinchet JC, et al. Fibrosis progression occurs in a subgroup of heavy drinkers with typical histological features. Aliment Pharmacol Ther 2007;25:1047-1054.

15. Carithers RL, McClain CJ. Alcoholic liver disease. In: Sleisenger and Fordtran's Gastrointestinal and liver disease pathophysiology diagnosis management, edited by Feldman M, Friedman LS, Brandt L. Philadelphia: Saunders Elsevier, 2016, p. $1409-1427$.

16. Creighton Mitchell T, McClain DA. Diabetes and hemochromatosis. Curr Diab Rep 2014;14:488.

17. Campuzano-Maya G. Estudio del paciente con hiperferritinemia. Medicina \& Laboratorio 2017;23:411-442. 